\title{
Mass Spectrometry Analysis of 2-Nitrophenylhydrazine Carboxy Derivatized Peptides
}

\author{
Junmei Zhang, Rowaida Al-Eryani, Haydn L. Ball
}

Protein Chemistry Technology Center, Department of Internal Medicine, University of Texas Southwestern Medical Center, Dallas, TX 75390-8816, USA

\begin{abstract}
Peptides with two or more basic residues, including those with post-translational modifications (PTMs), such as methylation and phosphorylation, can be highly hydrophilic and, therefore, are often difficult to be retained on a reversed-phase (RP) column. In addition, these highly hydrophilic peptides may carry two or more positive charges, which often fragment poorly upon collisionally activated dissociation (CAD), resulting in few sequence-specific ions. C-terminal rearrangement may also occur during CAD. Furthermore, some PTMs are labile and tend to be lost when subjected to CAD as is the case with phosphorylation on serine or threonine. To overcome the difficulties of separation, detection, and fragmentation of highly hydrophilic peptides, we report here the effect of carboxy group derivatization with 2-nitrophenylhydrazine (this strategy will be called NPHylation for simplicity). NPHylation significantly increases the hydrophobicity of the peptides, eliminates C-terminal rearrangement in all cases, and offers enhanced sensitivity in some cases. In addition, the CAD spectra of the resulting NPHylated peptides carry more sequence-specific ions due to significant reduction of sequence scrambling as observed for peptide EHAGVISVL. Furthermore, the different carboxy derivatives of this peptide undergo sequence scrambling to varying degrees, which clearly demonstrates that the $\mathrm{C}$-terminus has a profound effect on peptide fragmentation. Finally, sequence scrambling is a charge dependent phenomenon, which affects CAD of doubly charged peptides far more than their singly charged counterparts.
\end{abstract}

Key words: Peptide hydrophobicity, Hydrophilic peptide, Peptide carboxy group derivatization by NPHylation, C-terminal elimination, Sequence scrambling, Fragmentation pattern, Collisionally activated dissociation (CAD)

\section{Introduction}

$\mathrm{T}$ rypsin is one of the most commonly used enzymes for bottom-up proteomics. After a typical trypsin digestion, some peptides will have two or more basic groups, partially

Electronic supplementary material The online version of this article (doi:10.1007/s13361-011-0220-y) contains supplementary material, which is available to authorized users.

Correspondence to: Haydn L. Ball; e-mail: Haydn.Ball@utsouthwestern.edu due to one or more missed cleavages. The extent of missed cleavages increases when lysine or arginine carry posttranslational modifications (PTMs) such as lysine acetylation and/or lysine/arginine methylation. Peptides with two or more charged groups tend to be highly hydrophilic and are not retained well on a reversed-phase (RP) chromatography column. Phosphorylation is another example of a PTM that increases the hydrophilicity of the peptide on which it is attached. In addition to their very short retention times (if retained at all), these peptides often have limited proton mobility (due to strong sequestration of the ionizing proton 
(s) by basic amino acid side chains) and undergo reduced fragmentation along the peptide backbone upon CAD (in agreement with the mobile proton model introduced by Gaskell and Wysocki et al. [1, 2]), a commonly used low energy fragmentation technique for proteomics studies.

PTMs, including lysine acetylation [3-7], lysine/arginine methylation [8-11], and phosphorylation [12], are among the most widespread modifications and they regulate many cellular processes including cell survival and apoptosis, cellular differentiation, metabolism, and signal transduction. With increasing interest in such modifications and the increasing use of mass spectrometry for analysis of PTMs, efforts have been made to augment the hydrophobicity [13] and retention time [13, 14] of these highly hydrophilic peptides, or to apply an alternative fragmentation technique, e.g., electron transfer dissociation (ETD), for better mapping the PTMs like lysine/arginine methylation [14]. Since ETD has only been implemented on a few instruments to date and is not as widely available as CAD, we decided to evaluate other molecules better suited for ESI-MS/MS experiments, than reagents such as 1-(2-pyrimidyl)piperazine (PP) that have been used in MALDI-TOF peptide mass fingerprint applications [15].

In our studies a significant neutral loss was observed for the PP derivatized threonine phosphorylated peptide $\mathrm{TP}_{\mathrm{p}}$ TAPSLG upon CAD, which complicated MS/MS spectrum interpretation. Thus, a total of five alternative reagents were identified and tested, resulting in 2-nitrophenylhydrazine (2-NPH) becoming the molecule of choice. The 2-NPH derivatized peptides have higher hydrophobicity and longer retention time on a $\mathrm{C}_{18}$ column, exhibit considerably less neutral loss compared with their PP derivatized counterparts [13] in all cases, and have higher sensitivity in some cases. NPHylation (derivatization with 2$\mathrm{NPH}$ ) was also useful for understanding the fragmentation mechanisms of peptides.

\section{Experimental}

\section{Materials and Chemicals}

2-Nitrophenylhydrazine (98\%, 2-NPH), 2,6-dimethylpiperidine (98\%, 2,6-DMP), and 2-nitroaniline (98\%, 2-NAL) were purchased from Alfa Aesar (Ward Hill, MA, USA). 1-(2Pyrimidyl)piperazine (98\%, PP), 3-nitrophenylhydrazine hydrochloride $(98 \%, 3-\mathrm{NPH} . \mathrm{HCl})$, 4-nitrophenylhydrazine (97\%, 4-NPH), and $N$-(3-dimethylaminopropyl)- $N$ - ethylcarbodiimide hydrochloride (EDC) were obtained from SigmaAldrich (St. Louis, MO, USA). 1-Hydroxy-7-azabenzotriazole (99.9\%, HOAt) was purchased from GenScript (Piscataway, NJ, USA).

\section{Peptide Synthesis}

Peptides were synthesized on an Applied Biosystems 433 automated peptide synthesizer (Foster City, CA, USA), using optimized Fmoc chemistry [16]. Crude peptides were purified on a Waters 600 HPLC system (Milford, MA, USA) using a Vydac $\mathrm{C}_{18}$ semi-preparative column $(250 \mathrm{~mm} \times$ $10 \mathrm{~mm}$ ) at $3 \mathrm{~mL} / \mathrm{min}$ and $0 \%-100 \% B$ in $120 \mathrm{~min}$, where $A$ is water $/ 0.045 \%$ TFA and $B$ is acetonitrile $/ 0.036 \%$ TFA. The purified peptides were characterized using either MALDI-MS or ESI-MS.

\section{NPHylation of Peptides}

Each of the six derivatization reagents (PP, 2-NPH, 3-NPH. $\mathrm{HCl}$, 4-NPH, 2,6-DMP, and 2-NAL) was allowed to react with peptides according to a procedure reported previously [13]. For NPHylation with 2-NPH, the reagent of particular interest, the concentrations of 2-NPH, EDC, HOAt, and TFA were varied during optimization of the reaction conditions. The final conditions were as follows: 1.2 to $12.0 \mu \mathrm{L}$ of $0.5 \%$ 2-NPH in DMF, $4 \mu \mathrm{L}$ of $2 \mathrm{mg} / \mathrm{mL}$ EDC in DMF, and $3 \mu \mathrm{L}$ of $2 \mathrm{mg} / \mathrm{mL}$ HOAt were sequentially added to a solution of peptide $(<0.1 \mu \mathrm{g} / \mu \mathrm{L})$ in $50 \mu \mathrm{L}$ water. After vortexing for $30 \mathrm{~s}$, the reaction mixture was dried in a SpeedVac and desalted on $\mathrm{C}_{18}$ ZipTips (Millipore, Bedford, MA, USA) prior to LC-MS/MS analysis.

\section{Nano-LC-MS/MS Analysis}

Each peptide was reconstituted in 5-30 $\mu \mathrm{L}$ of HPLC buffer $A\left[0.1 \%\right.$ formic acid $/ 2 \%$ acetonitrile $/ 97.9 \% \mathrm{H}_{2} \mathrm{O}$ ( $\mathrm{vol} / \mathrm{vol} / \mathrm{vol})]$ and $1 \mu \mathrm{L}$ was injected into the Agilent 1100 nano flow HPLC system (Palo Alto, CA, USA). Mass analysis was performed on a ThermoFisher LTQ - 2D ion trap mass spectrometer (San Jose, CA, USA) equipped with a nano-ESI source. The capillary column $(10 \mathrm{~cm}$ length $\times 75 \mu \mathrm{m}$ i.d.) was home packed with Luna $\mathrm{C}_{18}$ resin (5 $\mathrm{m}$ particle size, $100 \AA$ pore diameter) (Phenomenex, Torrance, CA, USA). Peptides were eluted from the column using a gradient from $20 \%$ to $90 \%$ buffer B $\left[0.1 \%\right.$ formic acid $/ 90 \%$ acetonitrile $/ 9.9 \% \mathrm{H}_{2} \mathrm{O}$ ( $\mathrm{vol} / \mathrm{vol} /$ vol)] with a $40 \mathrm{~min}$ gradient. The eluted peptides were directly electro-sprayed into the LTQ spectrometer with MS/MS spectra acquired in a data dependent mode that cycled between MS and MS/MS of the eight strongest precursor ions. All the MS/MS experiments were performed with $32 \%$ normalized collision energy.

\section{Results and Discussion}

It has been reported that derivatization of carboxy groups with 1-(2-pyrimidyl)piperazine (PP) could improve the hydrophobicity/gas phase basicity and increase the ionization efficiency of phosphopeptides [13]. However, the effect this derivatization has on the fragmentation pattern of such peptides is unknown. Therefore, initial CAD studies were performed using both phosphorylated and underivatized peptides, comparing this data with that obtained using five 
other reagents. The results indicated that 2-NPH was the best for LC-MS/MS type experiments.

\section{Optimization of the Derivatization Reactions}

Each of the six reagents (see Figure 1 for their structures) was allowed to react with a model threonine phosphorylated peptide $\mathrm{TP}_{\mathrm{p}}$ TAPSLG under the same experimental conditions described by $\mathrm{Xu}$ et al. [13]. Two groups of the PP derivatized molecular ions at $\mathrm{m} / \mathrm{z} 969.4$ (singly charged) and
485.2 (doubly charged, minor component) with retention time of 13.2 and $14.6 \mathrm{~min}$, respectively, were observed for the model peptide (Figure 2a). Mainly one group of such ions with the longer RT was observed at higher intensities under the conditions optimized for 2-NPH. Significant neutral loss of 164Da occurred along with loss of the phosphate group upon CAD of the molecular ions (Figure 3a and $b$ ), which does not help with spectrum interpretation. Please note that only CAD spectra of the most abundant ions at $m / z 969.4$ are shown for simplicity. The CAD spectra of

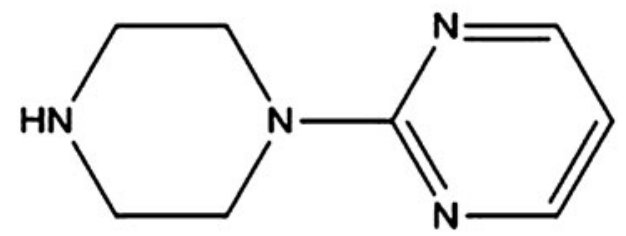

1-(2-pyrimidyl)piperazine (PP)<smiles>NNc1cccc([N+](=O)[O-])c1</smiles>

3-nitrophenylhydrazine hydrochloride (3-NPH. $\mathrm{HCl})$

. $\mathrm{HCl}$

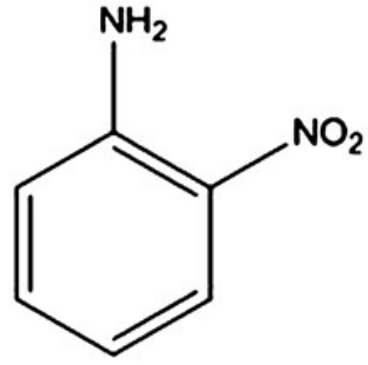

2-nitroaniline (2-NAL)

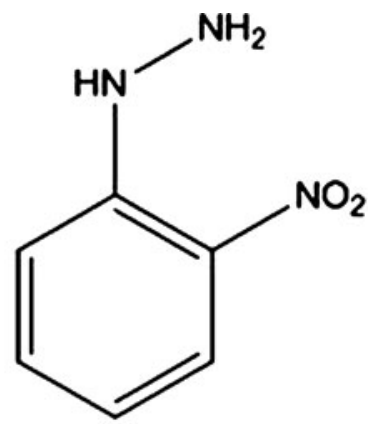

\section{2-nitrophenylhydrazine} (2-NPH)<smiles>NNc1ccc([N+](=O)[O-])cc1</smiles>

4-nitrophenylhydrazine (4-NPH)<smiles>CC1CCCC(C)N1</smiles>

2,6-dimethylpiperidine (2.6-DMP)

Figure 1. Structures of the derivatization reagents tested in this work 


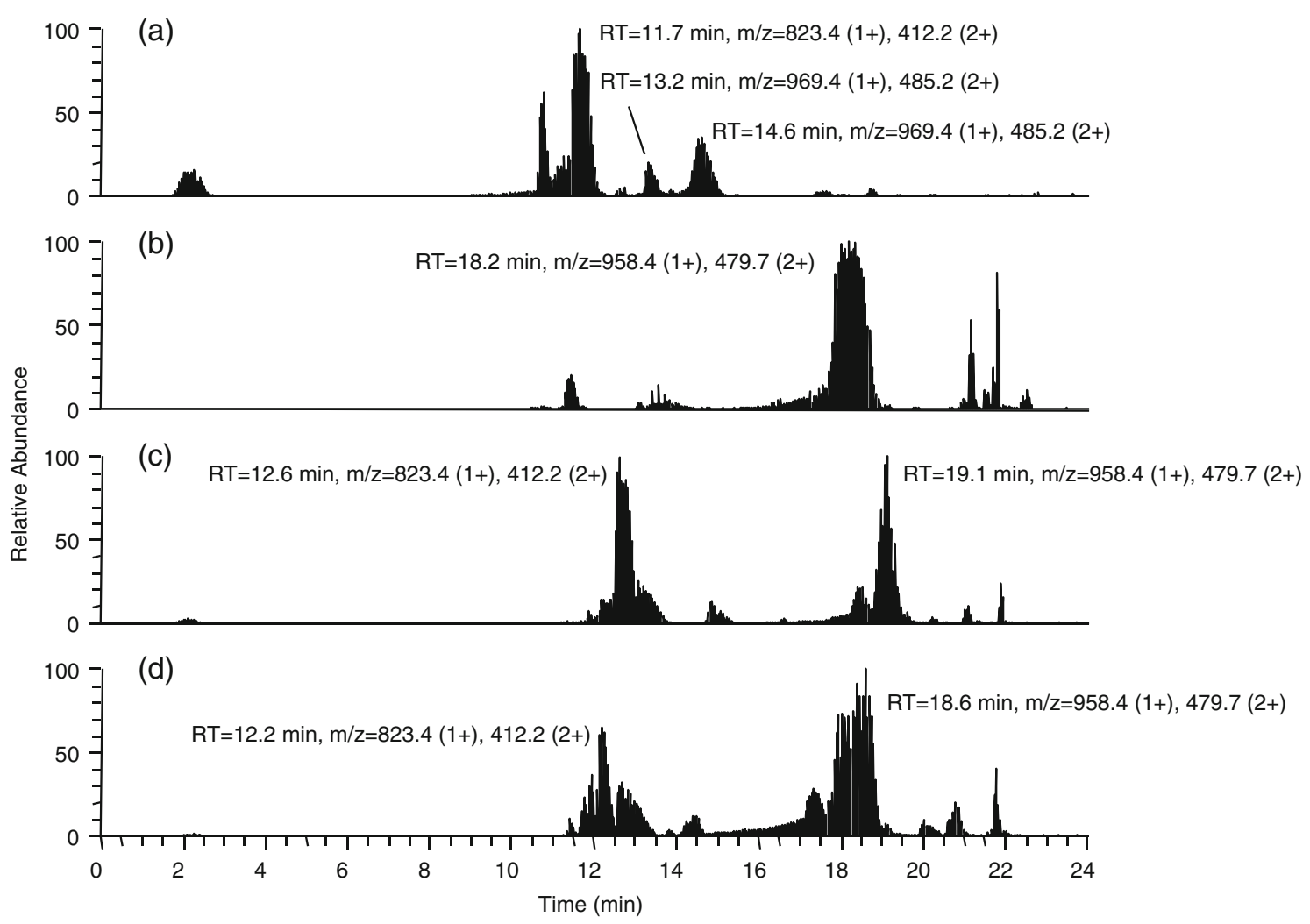

Figure 2. Total ion chromatograms of threonine phosphorylated peptide TP $\mathrm{P}_{\mathrm{p}} \mathrm{TAPSLG}$ after derivatization with the following reagents: (a) 1-(2-pyrimidyl)piperazine (PP), (b) 2-nitrophenylhydrazine (2-NPH), (c) 3-nitrophenylhydrazine hydrochloride (3$\mathrm{NPH} . \mathrm{HCl}$ ), and (d) 4-nitrophenylhydrazine (4-NPH)
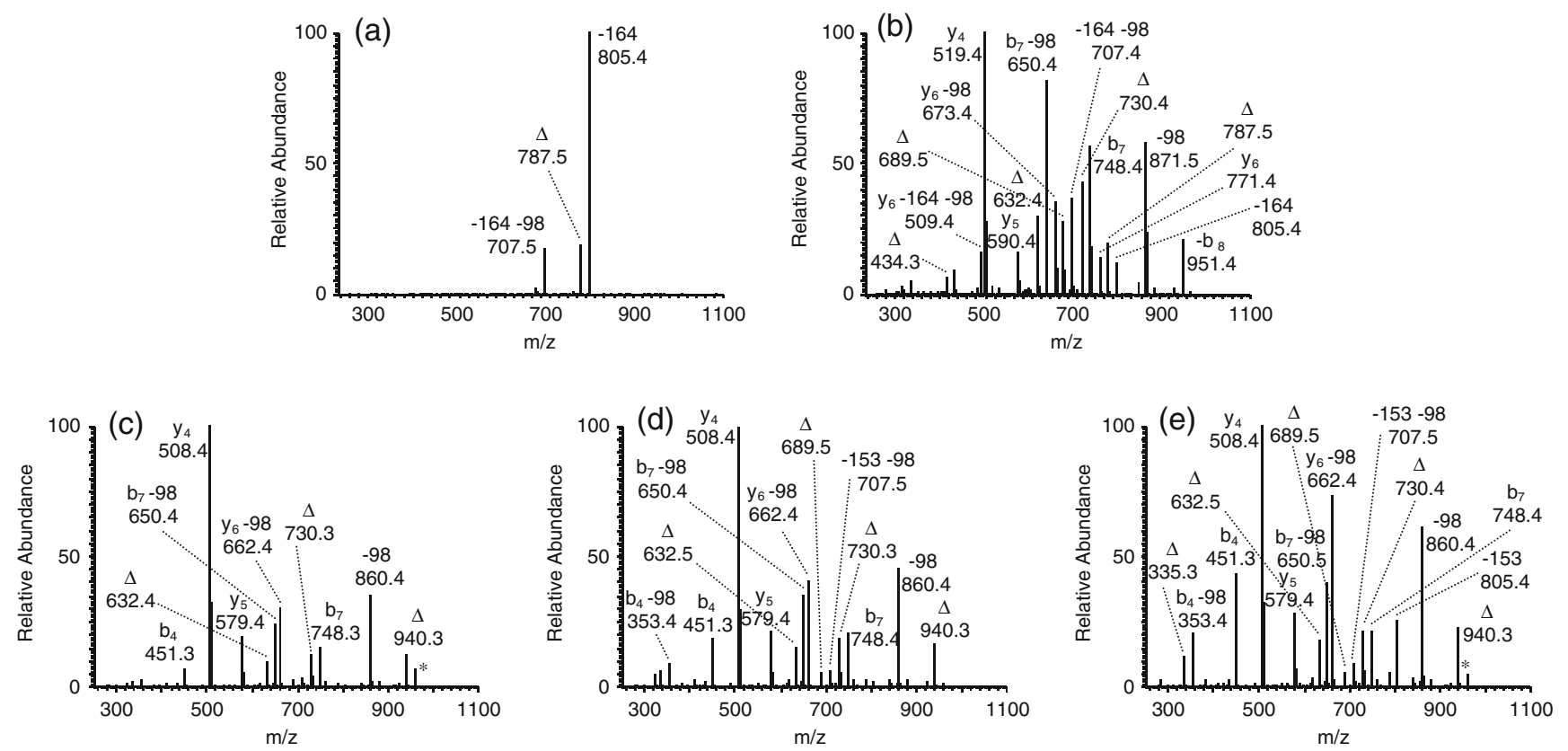

Figure 3. CAD spectra of singly charged peptide TP TAPSLG after derivatization with the following reagents: (a) and (b) 1-(2pyrimidyl)piperazine (PP) with RT $13.2 \mathrm{~min}$ (a) and $14.6 \mathrm{~min}$ (b), respectively, (c) 2-nitrophenylhydrazine (2-NPH), (d) 3nitrophenylhydrazine hydrochloride (3-NPH.HCl), and (e) 4-nitrophenylhydrazine (4-NPH). The open triangle $(\Delta)$ designates "b", "y" or "a" ions with water and/or ammonia loss. The asterisk $\left(^{*}\right)$, when present, designates the precursor ion. The same nomenclature is used for all subsequent figures 
the corresponding doubly charged ions at $\mathrm{m} / \mathrm{z} 485.2$ are reported in the Supplemental Information section (SF1). The other PP derivatized peptides also have more neutral loss of the derivatization reagent (PP: $164 \mathrm{Da}$ in this case) than the 2-NPH derivatized counterparts (2-NPH: 153 Da) (Figure 3c). Thus, derivatization of peptides with PP may significantly boost the ionization efficiency of the phosphopeptides for MALDI peptide mass fingerprint experiments, yet it is not a method of choice if CAD has to be used for identification of the peptides when only a low resolution instrument is available.

Since the first reports in the early 1990s [17-20], 2-NPH and 2-NPH.HCl (2-nitrophenylhydrazine hydrochloride) have been used to derivatize fatty acids and other carboxylic acids, aldehydes, and ketones, for improved retention properties on a RP column and for more sensitive UV detection. Based on the carboxy group reactivity of 2-NPH and 2-NPH.HCl and their structurally similar homologs, we investigated whether or not derivatization could facilitate the identification of peptides by MS/MS by generating more sequence-specific fragment ions.

Among the five reagents tested, 2,6-dimethylpiperidine (2,6-DMP) and 2-nitroaniline (2-NAL) did not produce the desired derivatization products but 2-NPH, 3-NPH.HCl, and 4-NPH converted the test peptides to their NPHylated products (peptide $+135 \mathrm{Da}$ ), which have a longer RT than both their underivatized and PP-derivatized counterparts (Figure 2). While the RT of the three NPHylation products was similar, the NPHylation reaction seemed to be more complete when 2-NPH was used (Figure 2b versus Figure 2c or d). More importantly, the extent of neutral loss of $153 \mathrm{Da}$ (the NPHylation reagent) was the least significant when the peptides were NPHylated with 2-NPH (Figure 3 and SF1). When a serine phosphorylated peptide TPTAP $_{\mathrm{p}} \mathrm{SLG}$ was NPHylated with 2-NPH, its CAD spectra also showed very minimal loss of $153 \mathrm{Da}$ (SF2). In addition to the phosphopeptides, three tryptic peptides were tested: AYPGFK, GRIDKPILK and ISQAVHAAHAEINEAGR, and similar trends of neutral loss of 153 Da were observed. Therefore, 2-NPH was chosen as the reagent for all subsequent experiments.

\section{Selectivity and Derivatization Efficiency of 2-NPH}

For peptides that do not contain aspartic or glutamic acid, 2$\mathrm{NPH}$ reacts rapidly with the C-terminus of the peptides. One such example is shown in Figure $4 \mathrm{a}$ for N-terminal
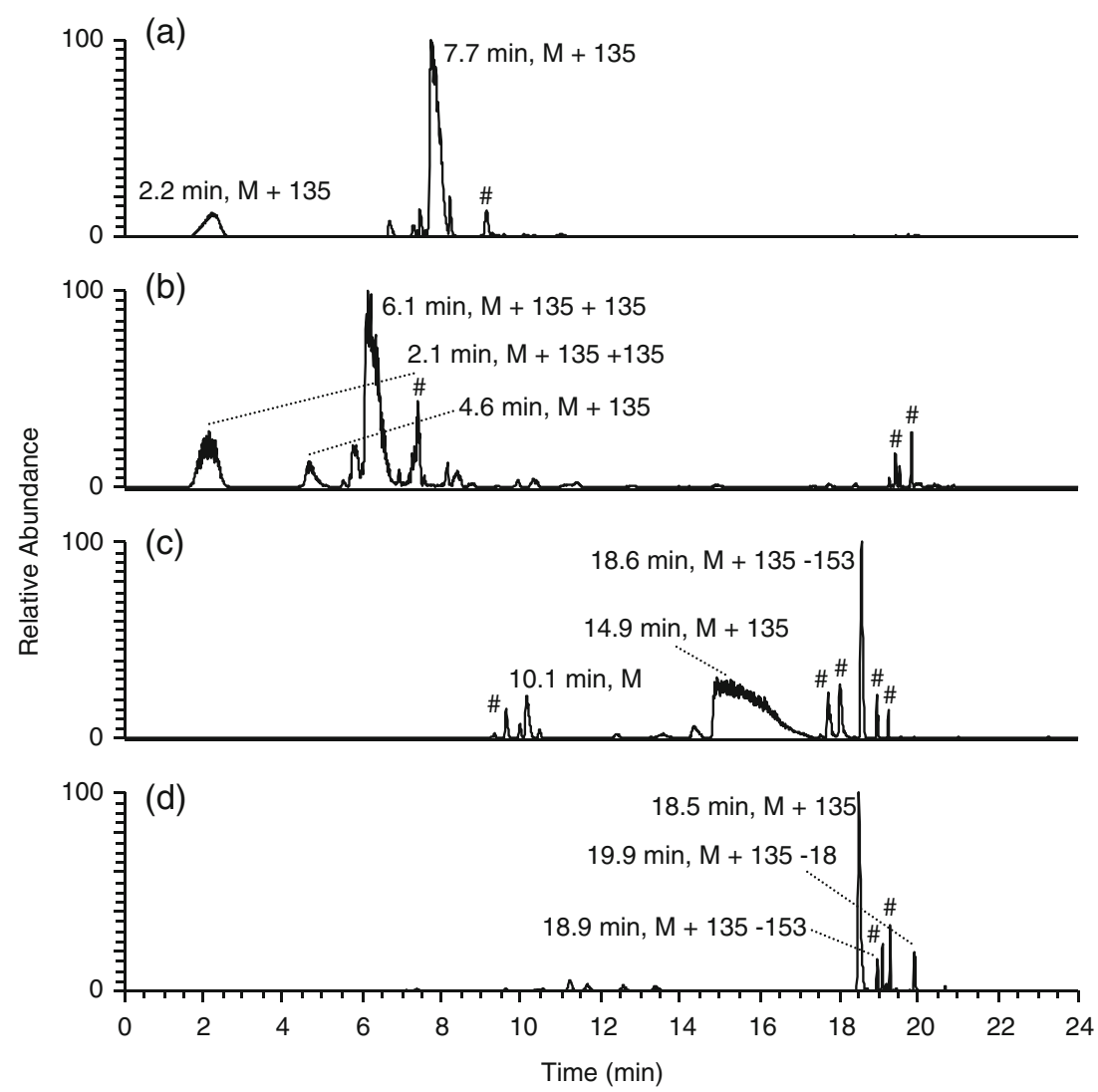

Figure 4. Selectivity of peptides for derivatization with 2-nitrophenylhydrazine (2-NPH): (a) Ac-KKKANLQYYA, (b) VHGQPHQDTK, (c) SIINFEKL, and (d) EYIPTVF. For simplicity, the peptides are labeled with M and their NPHylation products are labeled with $\mathrm{M}+135$, and $\mathrm{M}+135+135$. Neutral loss of $2-\mathrm{NPH}$ and water are labeled with -153 and -18 , respectively. Peaks irrelevant to the peptides of interest are labeled with the number symbol (\#) 
acetylated peptide Ac-KKKANLQYYA. When an aspartic and/or glutamic acid residue exists in a peptide, 2-NPH predominately reacts with the $\mathrm{C}$-terminus, yet it does show some reactivity towards carboxy side chain moiety of these amino acids, though the extent of such derivatization varies with the identity and location of these groups. For example, the major product of peptide VHGQPHQDTK is addition of $2 * 135 \mathrm{Da}$ (Figure $4 \mathrm{~b}$ ), while that of SIINFEKL is addition of $1 * 135 \mathrm{Da}$ (Figure 4c), with a fragmentation pattern that agrees with derivatization of the C-terminus (SF3). It should be pointed out that due to the impurities in our synthetic peptide preparations, there are some peaks present that are not related to the peptides of interest, and they are labeled with the number symbol (\#).

Except for SIINFEKL, the other three peptides were almost completely converted to their NPHylation products after 2-NPH derivatization (Figure 4). It is rather difficult to estimate the reaction yield since the peptides and their NPHylated products have different RT, peak shapes, and sensitivities. Our best estimation is that the efficiency of NPHylation reaction is about $80 \%$ or higher. Besides the desired NPHylation derivatives, loss of 2-NPH from the derivatives has been sometimes observed as a side product (Figure $4 \mathrm{c}$ and d). In addition, loss of water from the NPHylated peptides was observed as a minor product when glutamic acid is the N-terminal residue such as EYIPTVF, in agreement with the literature [21-23] (Figure 4d).

\section{NPHylation Increases Peptide Hydrophobicity}

NPHylation with 2-NPH significantly improves the hydrophobicity of the peptides and increases their retention time on a RP column. For example, the RT of threonine phosphorylated peptide $\mathrm{TP}_{\mathrm{p}}$ TAPSLG increased from $\sim 11.5 \mathrm{~min}$ to $\sim 18.2 \mathrm{~min}$ after NPHylation with $2-\mathrm{NPH}$ (Figure 2b), which is longer than the equivalent PP derivatized analogs, that eluted at $\sim 13.2$ or $14.6 \mathrm{~min}$ (Figure 2a). The RT of the underivatized versus NPHylated peptides listed in Figure 4 follows the same trend: 5.9 versus $7.7 \mathrm{~min}$ for peptide Ac-KKKANLQYYA; 2.1 versus $4.6 \mathrm{~min}$ (mono-NPHylated) or $6.1 \mathrm{~min}$ (di-NPHylated sequence) for VHGQPHQDTK; 9.8 versus 14.9 min for SIINFEKL; and 11.6 versus $18.5 \mathrm{~min}$ for EYIPTVF. Please note that Ac-KKKANLQYYA and VHGQPHQDTK are highly hydrophilic peptides that are difficult to be retained on a RP column, especially VHGQPHQDTK. Thus, NPHylation facilitates the detection of these highly hydrophilic peptides that would otherwise be lost in the void volume, as a result of the increased hydrophobicity imparted by this chemical modification.

\section{NPHylation Increases the Peptide Sensitivity in Some Cases}

To quickly assess the sensitivity of NPHylation, model peptides and their NPHylated counterparts were mixed at
$1: 1$ ratio before injection and eluted with $1.2 \mu \mathrm{L} / \mathrm{min}$ $90 \%$ B (to reduce the extent of peak broadening for a more objective evaluation of sensitivity). The ratio of ion intensity/peak height of the NPHylation products versus underivatized peptides was $1.2,1.4,15.7,12.5$, and the peak area ratio was $1.4,1.5,6.3$, and 2.5 , respectively (Figure 5). Thus, the sensitivities vary from increasing slightly or up to several fold upon NPHylation. Though it is not ideally affecting sensitivity to the same extent, NPHylation does offer better detection limits for some hydrophilic peptides. More importantly NPHylation provides better retention of hydrophilic peptides, increased hydrophobicity, and significant reduction of non sequence-specific fragment ions as described below.

\section{NPHylation Reduces Non-Sequence-Specific Fragment Ions}

Two major sources of non-sequence-specific fragment ions are C-terminal elimination and sequence scrambling, which can be blocked or reduced by NPHylation, respectively.

C-terminal Elimination (C-terminal Rearrangement) Hydrophilic peptides with two or more basic groups have a tendency to undergo C-terminal elimination (loss of the C-terminal residue) upon CAD, a phenomenon already documented in the literature [24-36] and recently found to be a charge-dependent, side-chain assisted C-terminal rearrangement [29]. By blocking the C-terminal carboxy group, NPHylation completely eliminates such $\mathrm{C}$-terminal rearrangement for both charge states (SF4), once again demonstrating that a free C-terminal carboxy group is required for C-terminal elimination side reactions [26, 29, 36]. Therefore, NPHylation not only improves the hydrophobicity of hydrophilic peptides but also eliminates an undesirable $\mathrm{C}$-terminal rearrangement, making NPHylation an attractive alternative for tandem mass spectrometry studies.

Sequence Scrambling In addition to C-terminal rearrangement, sequence scrambling is another phenomenon that produces non-sequence-specific fragment ions, and thus limits our abilities for correct peptide identification [3758]. It has been found that $\mathrm{N}$-terminal acetylation eliminates sequence scrambling $[37,41,55]$, as well as the type of amino acid side-chains (not including the C-terminus), i.e., acidic, basic, or amide, and their positions apparently influence the extent of sequence scrambling $[46,47,53$, 55]. We investigated the effect of NPHylation on this phenomenon at the MS/MS level.

Taking peptide EHAGVISVL as an example, several sequence scrambling ions can be seen from the CAD spectrum of the doubly charged precursor ion: $\mathrm{b}_{8}^{0}-\mathrm{I}(\mathrm{m} / \mathrm{z}$ 662.3 , relative abundance $31 \%), b_{8}-\mathrm{I}(\mathrm{m} / \mathrm{z} 680.3,7 \%)$, and $\mathrm{b}_{8}^{0}-\mathrm{IV}(\mathrm{m} / \mathrm{z} 563.4,1 \%)$, which is in agreement with the 


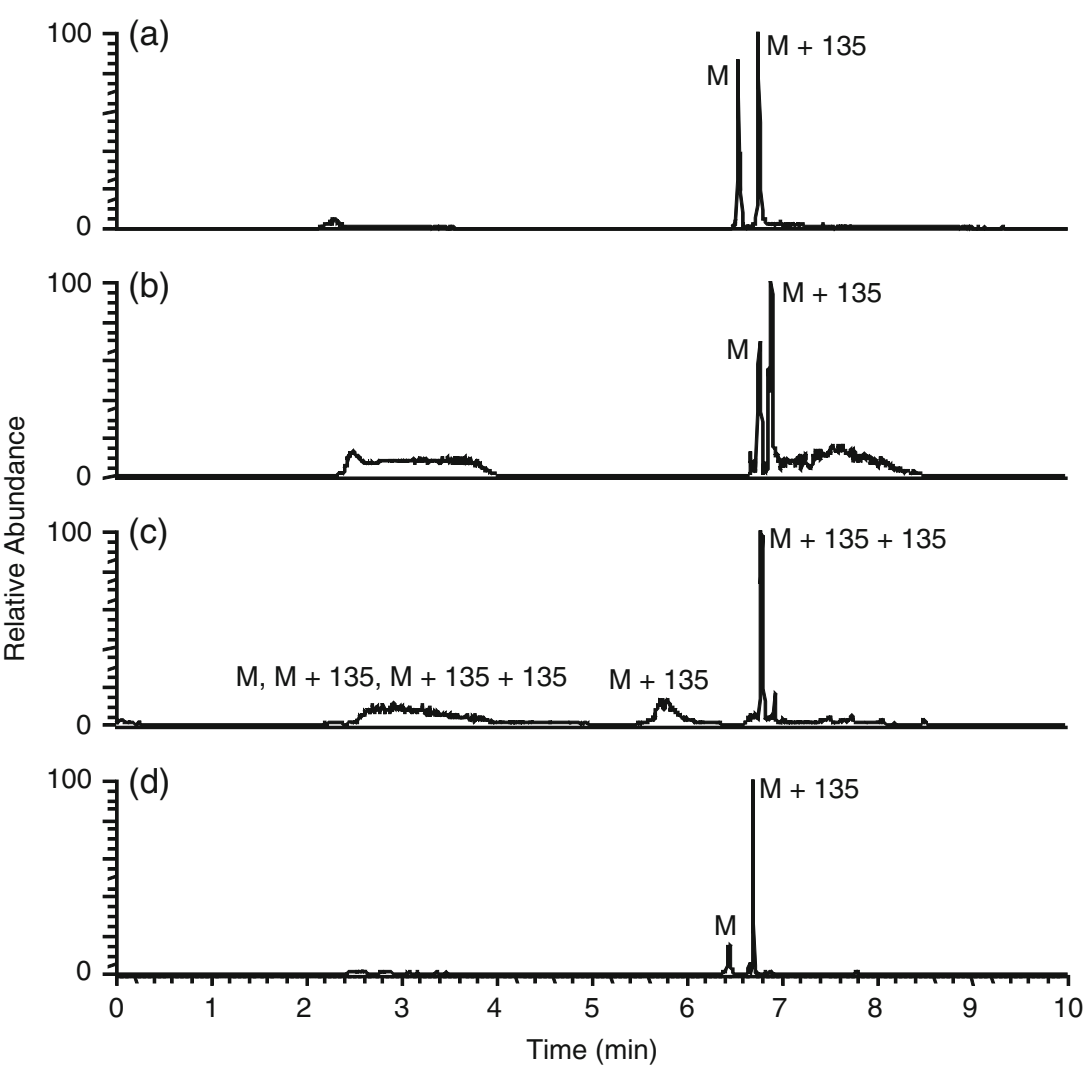

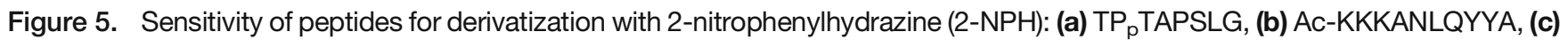
VHGQPHQDTK, and (d) K(Ac)SAPATGGVK. They were eluted with $90 \%$ B at $1.2 \mu \mathrm{L} / \mathrm{min}$ for easy comparison of sensitivity

literature [41]. After NPHylation, the relative abundances of the non-sequence-specific ions are decreased over 6 -fold to $5 \%, 1 \%$, and $<1 \%$ (not visible), respectively (Figure $6 \mathrm{~b}$ ), significant enough to suggest that NPHylation can reduce the extent of sequence scrambling at the MS/MS level. Similar reduction of sequence scrambling was also observed for 4-NPH and 3-NPH.HCl derivatized counterparts of the same peptide (SF5).

In addition to the above three NPH reagents, PP derivatization reduced the extent of sequence scrambling such that no obvious scrambling ions are detected (Figure 6c). To demonstrate that such an effect is not solely due to the bulkiness of the modified $\mathrm{C}$-terminus, the $\mathrm{C}$ terminally amidated version of the peptide (EHAGVISVL$\mathrm{NH}_{2}$ ) was synthesized and subjected to CAD. Interestingly, loss of ammonia became the dominant fragmentation pathway as observed before [42], and no obvious sequence scrambling was observed at the MS/MS level (Figure 6d), clearly indicating that factors other than steric hindrance of the $\mathrm{C}$-terminus affect the fragmentation of protonated peptides.

Moreover, sequence scrambling is more significant for doubly charged ions (C-terminal rearrangement is generally observable with singly charged ions). For example, peptide EHAGVISVL and each of its three NPH derivatives (2-NPH, 3-NPH.HCl, and 4-NPH) undergo sequence scrambling at the +2 charge state though to a different extent (Figure 6a and b, SF5), however, their singly charged counterparts do not seem to exhibit this same phenomenon (SF6). Since peptide identification relies heavily on CAD spectra of doubly charged ions and doubly charged ions are more likely to undergo sequence scrambling than their singly charged counterparts, our efforts to reduce the extent of (if not eliminate) sequence scrambling and understand its underlying mechanism(s) are well rationalized. Sequence scrambling is believed to involve formation of a cyclic intermediate produced by the nucleophilic attack of the N-terminal nitrogen over an electrophilic carbonyl carbon near the C-terminus and its subsequent reopening at different positions [39, 42]. It is beyond the scope of this work to study the mechanisms of sequence scrambling, but we can see that the phenomenon becomes less favored at the MS/MS level when the protons become sequestered/less mobile by a nucleophilic modification, such as NPHyation or amidation of the C-terminus. Anecdotally, it has been shown by Harrison and his co-workers that histidine containing $b$ ions undergo sequence scrambling, which is observable at the MS/MS/MS level [53]. Thus, care is needed when comparing sequence scrambling studies at 

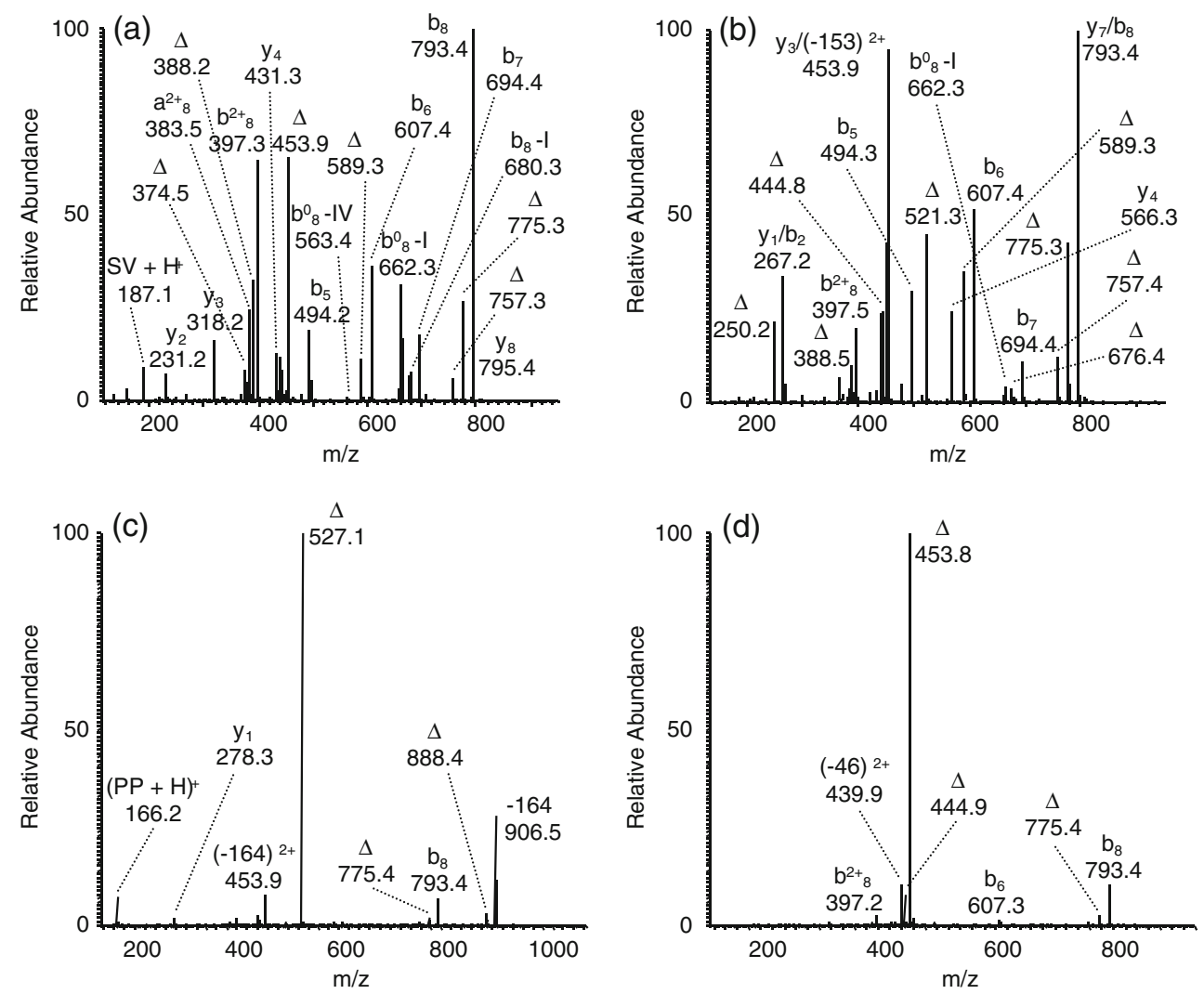

Figure 6. CAD spectra of doubly charged peptide EHAGVISVL: (a) without derivatization, (b) after derivatization with 2-nitrophenylhydrazine (2-NPH), (c) 1-(2-pyrimidyl) piperazine (PP), and (d) amidation of the C-terminus

different stages of tandem mass spectrometry. As a result of the reduction in proton mobility, the singly charged peptides undergo sequence scrambling to a lesser extent. Although it is not our initial intention to study in detail the mechanism of sequence scrambling or neutral loss, our data suggest that altering the proton availability and/ or mobility of a peptide by derivatizing its C-terminus and/or changing its charge state can have a profound effect on peptide fragmentation. That is to say, the Cterminus can play an important role in the process of sequence scrambling.

It is interesting to point out that scientists have started to study the effect of sequence scrambling on a proteomics scale [57, 59, 60], which inevitably involves a database search engine, such as Mascot. The current version of Mascot 2.3 is "not trying to find all possible matches in a spectrum" (personal communications with technical support) such that similar scores can be obtained for a peptide with and without considering sequence scrambling ions. At least partially due to the way Mascot scores, our NPHylation strategy does not give much improvement in peptide scoring even though manual inspection gives a different picture. Though it is still debatable, we believe more sophisticated software that better handles neutral losses will benefit the proteomics community and strategies like NPHylation will become more attractive.

\section{Conclusion}

For successful bottom-up proteomics analysis, effective separation on a RP column, sensitive detection, and sequence-specific fragmentation of peptides are required. Hydrophilic peptides with multiple charged groups or carrying PTMs can easily elude detection and identification since they are not readily retained on the column, and may produce non-sequence-specific fragment ions. Furthermore, negatively charged PTMs such as phosphorylation and sulfation may suppress ionization in the mass spectrometer resulting in reduced sensitivity. To address these issues, 2NPH was used as a derivatization reagent to react with the carboxy group(s) of the peptides, with the $\mathrm{C}$-terminus as the preferred site of reaction. NPHylation significantly improves the hydrophobicity, increases the retention times in all cases, and offers higher sensitivity for some peptides. Moreover, NPHylation eliminates C-terminal rearrangement reactions and reduces the extent of sequence scrambling, thereby generating more sequence-specific fragment ions. By comparing the fragmentation patterns of the original and NPHylated peptide pairs, insights into the mechanism of 
peptide fragmentation, including sequence scrambling, may be obtained.

\section{References}

1. Burlet, O., Yang, C.Y., Gaskell, S.J.: Influence of cysteine to cysteic acid oxidation on the collision-activated decomposition of protonated peptides: Evidence for intraionic interactions. J. Am. Soc. Mass Spectrom. 3, 337-344 (1992)

2. Dongre, A.R., Jones, J.L., Somogyi, A., Wysocki, V.H.: Influence of peptide composition, gas-phase basicity, and chemical modification on fragmentation efficiency: Evidence for the mobile proton model. J. Am. Chem. Soc. 118, 8365-8374 (1996)

3. Haigis, M.C., Guarente, L.P.: Mammalian sirtuins - emerging roles in physiology, aging, and calorie restriction. Gene Dev. 20, 2913-2921 (2006)

4. Hake, S.B., Xiao, A., Allis, C.D.: Linking the epigenetic 'language' of covalent histone modifications to cancer. Br. J. Cancer 90, 761-769 (2004)

5. Kouzarides, T.: Acetylation: A regulatory modification to rival phosphorylation? EMBO J. 19, 1176-1179 (2000)

6. McKinsey, T.A., Olson, E.N.: Cardiac histone acetylation-therapeutic opportunities abound. Trends Genet. 20, 206-213 (2004)

7. Yang, X.J.: The diverse superfamily of lysine acetyltransferases and their roles in leukemia and other diseases. Nucleic Acids Res. 32, 959976 (2004)

8. Bedford, M.T., Richard, S.: Arginine methylation: An emerging regulator of protein function. Mol. Cell. 18(3), 263-272 (2005)

9. Lake, A.N., Bedford, M.T.: Protein methylation and DNA repair. Mutat. Res. Fund. Mol. M. 618, 91-101 (2007)

10. Pahlich, S., Zakaryan, R.P., Gehring, H.: Protein arginine methylation: Cellular functions and methods of analysis. Biochem. Biophys. ActaProteins Proteom. 1764, 1890-1903 (2006)

11. Paik, W.K., Paik, D.C., Kim, S.: Historical review: The field of protein methylation. Trends Biochem. Sci. 32, 146-152 (2007)

12. Johnson, S.A., Hunter, T.: Kinomics: Methods for deciphering the kinome. Nat. Methods 2, 17-25 (2005)

13. Xu, Y., Zhang, L., Lu, H., Yang, P.: Mass spectrometry analysis of phosphopeptides after peptide carboxy group derivatization. Anal. Chem. 80, 8324-8328 (2008)

14. Snijders, A.P.L., Hung, M.L., Wilson, S.A., Dickman, M.J.: Analysis of arginine and lysine methylation utilizing peptide separations at neutral $\mathrm{pH}$ and electron transfer dissociation mass spectrometry. J. Am. Soc. Mass Spectrom. 21, 88-96 (2010)

15. Qiao, X., Sun, L., Chen, L., Zhou, Y., Yang, K., Liang, Z., Zhang, L., Zhang, Y.: Piperazines for peptide carboxyl group derivatization: Effect of derivatization reagents and properties of peptides on signal enhancement in matrix-assisted laser desorption/ionization mass spectrometry. Rapid Commun. Mass Spectrom. 25, 639-646 (2011)

16. Ball, H.L., Mascagni, P.: Chemical synthesis and purification of proteins: A methodology. Int. J. Pept. Protein Res. 48, 31-47 (1996)

17. Coenen, A., Kerkhoff, M.J.G., Heringa, R.M., Vanderwal, S.: Comparison of several methods for the determination of trace amounts of polar aliphatic monocarboxylic acids by high-performance liquid-chromatography. J. Chromatogr. 593, 243-252 (1992)

18. Kondoh, Y., Yamada, A., Takano, S.: Determination of nonionic surfactants with ester groups by high-performance liquid-chromatography with postcolumn derivatization. J. Chromatogr. 541, 431-441 (1991)

19. Miwa, H., Yamamoto, M.: Liquid-chromatographic determination of free and total fatty-acids in milk and milk-products as their 2nitrophenylhydrazides. J. Chromatogr. 523, 235-246 (1990)

20. Miwa, H., Yamamoto, M., Asano, T.: High-performance liquidchromatographic analysis of fatty-acid compositions of platelet phospholipids as their 2-nitrophenylhydrazides. J. Chromatogr. B 568, 2534 (1991)

21. Winter, D., Lehmann, W.D.: Sequencing of the 13 structurally isomeric quartets of N-terminal dipeptide motifs in peptides by collision-induced dissociation. Proteomics 9, 2076-2084 (2009)

22. Winter, D., Lehmann, W.D.: Individual $b_{2}$ ion fragmentation profiles combined with AspN digestion improve $\mathrm{N}$-terminal peptide sequencing. Anal. Bioanal. Chem. 393, 1587-1591 (2009)
23. Godugu, B., Neta, P., Simon-Manso, Y., Stein, S.E.: Effect of Nterminal glutamic acid and glutamine on fragmentation of peptide ilons. J. Am. Soc. Mass Spectrom. 21, 1169-1176 (2010)

24. Hiserodt, R.D., Brown, S.M., Swijter, D.F.H., Hawkins, N., Mussinan, C.J.: A study of $b(1)+\mathrm{H}_{2} \mathrm{O}$ and $\mathrm{b}(1)$-ions in the product ion spectra of dipeptides containing $\mathrm{N}$-terminal basic amino acid residues. J. Am. Soc. Mass Spectrom. 18, 1414-1422 (2007)

25. Sharp, J.S., Tomer, K.B.: Formation of $\left[\mathrm{b}_{(\mathrm{n}-1)}+\mathrm{OH}+\mathrm{H}\right]^{+}$ion structural analogs by solution-phase chemistry. J. Am. Soc. Mass Spectrom. 16, 607-621 (2005)

26. Thorne, G.C., Ballard, K.D., Gaskell, S.J.: Metastable decomposition of peptide $[\mathrm{M}+\mathrm{H}]^{+}$ions via rearrangement involving loss of the Cterminal amino-acid residue. J. Am. Soc. Mass Spectrom. 1, 249-257 (1990)

27. Thorne, G.C., Gaskell, S.J.: Elucidation of some fragmentations of small peptides using sequential mass spectrometry on a hybrid instrument. Rapid Commun Mass Spectrom. 3, 217-21 (1989)

28. Tsaprailis, G., Nair, H., Somogyi, A., Wysocki, V.H., Zhong, W.Q., Futrell, J.H., Summerfield, S.G., Gaskell, S.J.: Influence of secondary structure on the fragmentation of protonated peptides. J. Am. Chem. Soc. 121, 5142-5154 (1999)

29. Zhang, J., Chen, Y., Zhang, Z., Xing, G., Wysocka, J., Zhao, Y.: MS/ $\mathrm{MS} / \mathrm{MS}$ reveals false positive identification of histone serine methylation. $J$. Proteome Res. 9, 585-594 (2010)

30. Deery, M.J., Summerfield, S.G., Buzy, A., Jennings, K.R.: A Mechanism for the loss of $60 \mathrm{u}$ from peptides containing an arginine residue at the C-terminus. J. Am. Soc. Mass Spectrom. 8, 253-261 (1997)

31. Dikler, S., Kelly, J.W., Russell, D.H.: Improving mass spectrometric sequencing of arginine-containing peptides by derivatization with acetylacetone. J. Mass Spectrom. 32, 1337-1349 (1997)

32. Gonzalez, J., Besada, V., Garay, H., Reyes, O., Padron, G., Tambara, Y., Takao, T., Shimonishi, Y.: Effect of the position of a basic amino acid on C-terminal rearrangement of protonated peptides upon collisioninduced dissociation. J. Mass Spectrom. 31, 150-158 (1996)

33. Vachet, R.W., Asam, M.R., Glish, G.L.: Secondary interactions affecting the dissociation patterns of arginine-containing peptide ions. J. Am. Chem. Soc. 118, 6252-6256 (1996)

34. Ballard, K.D., Gaskell, S.J.: Intramolecular [O-18] isotopic exchange in the gas-phase observed during the tandem mass-spectrometric analysis of peptides. J. Am. Chem. Soc. 114, 64-71 (1992)

35. Bythell, B.J., Csonka, I.P., Suhai, S., Barofsky, D.F., Paizs, B.: Gas-phase structure and fragmentation pathways of singly protonated peptides with N-terminal arginine. J. Phys. Chem. B 114, 15092-15105 (2010)

36. Farrugia, J.M., O'Hair, R.A.J.: Involvement of salt bridges in a novel gas phase rearrangement of protonated arginine-containing dipeptides which precedes fragmentation. Int. J. Mass Spectrom. 222, 229-242 (2003)

37. Harrison, A.G.: Peptide sequence scrambling through cyclization of $b$ (5) ions. J. Am. Soc. Mass Spectrom. 19, 1776-1780 (2008)

38. Harrison, A.G.: To $b$ or not to $b$ : The ongoing saga of peptide $b$ ions. Mass Spectrom. Rev. 28, 640-654 (2009)

39. Harrison, A.G., Young, A.B., Bleiholder, C., Suhai, S., Paizs, B.: Scrambling of sequence information in collision-induced dissociation of peptides. J. Am. Chem. Soc. 128, 10364-10365 (2006)

40. Vachet, R.W., Bishop, B.M., Erickson, B.W., Glish, G.L.: Novel peptide dissociation: Gas-phase intramolecular rearrangement of internal amino acid residues. J. Am. Chem. Soc. 119, 5481-5488 (1997)

41. Yague, J., Paradela, A., Ramos, M., Ogueta, S., Marina, A., Barahona, F., de Castro, J.A.L., Vazquez, J.: Peptide rearrangement during quadrupole ion trap fragmentation: Added complexity to MS/MS spectra. Anal. Chem. 75, 1524-1535 (2003)

42. Bleiholder, C., Osburn, S., Williams, T.D., Suhai, S., Van Stipdonk, M., Harrison, A.G., Paizs, B.: Sequence-scrambling fragmentation pathways of protonated peptides. J. Am. Chem. Soc. 130, 1777417789 (2008)

43. Chen, X., Yu, L., Steill, J.D., Oomens, J., Polfer, N.C.: Effect of peptide fragment size on the propensity of cyclization in collision-induced dissociation: Oligoglycine b2-b8. J. Am. Chem. Soc. 131, 18272-18282 (2009)

44. Cordero, M.M., Houser, J.J., Wesdemiotis, C.: The neutral products formed during backbone fragmentations of protonated peptides in tandem mass-spectrometry. Anal. Chem. 65, 1594-1601 (1993) 
45. Molesworth, S., Osburn, S., Van Stipdonk, M.J.: Influence of size on apparent scrambling of sequence during CID of b-type ions. J. Am. Soc. Mass Spectrom. 20, 2174-2181 (2009)

46. Molesworth, S., Osburn, S., Van Stipdonk, M.J.: Influence of amino acid side chains on apparent selective opening of cyclic b5 ions. J. Am. Soc. Mass Spectrom. 21, 1028-1036 (2010)

47. Molesworth, S.P., Van Stipdonk, M.J.: Apparent inhibition by arginine of macrocyclic b ion formation from singly charged protonated peptides. J. Am. Soc. Mass Spectrom. 21, 1322-1328 (2010)

48. Tang, X.J., Boyd, R.K.: Rearrangements of doubly-charged acylium ions from lysyl and ornithyl peptides. Rapid Commun. Mass Spectrom. 8, 678-686 (1994)

49. Nold, M.J., Cerda, B.A., Wesdemiotis, C.: Proton affinities of the Nand $\mathrm{C}$-terminal segments arising upon the dissociation of the amide bond in protonated peptides. J. Am. Soc. Mass Spectrom. 10, 1-8 (1999)

50. Nold, M.J., Wesdemiotis, C., Yalcin, T., Harrison, A.G.: Amide bond dissociation in protonated peptides. Structures of the Nterminal ionic and neutral fragments. Int. J. Mass Spectrom. 164, 137-153 (1997)

51. Paizs, B., Suhai, S.: Towards understanding the tandem mass spectra of protonated oligopeptides. 1. Mechanism of amide bond cleavage. J. Am. Soc. Mass Spectrom. 15, 103-113 (2004)

52. Yalcin, T., Khouw, C., Csizmadia, I.G., Peterson, M.R., Harrison, A.G.: Why are b ions stable species in peptide spectra? J. Am. Soc. Mass Spectrom. 6, 1165-1174 (1995)
53. Bythell, B.J., Knapp-Mohammady, M., Paizs, B., Harrison, A.G.: Effect of the His residue on the cyclization of b ions. J. Am. Soc. Mass Spectrom. 21, 1352-1363 (2010)

54. Bythell, B.J., Suhai, S., Somogyi, A., Paizs, B.: Proton-driven amide bond-cleavage pathways of gas-phase peptide ions lacking mobile protons. J. Am. Chem. Soc. 131, 14057-14065 (2009)

55. Jia, C.X., Qi, W., He, Z.M.: Cyclization reaction of peptide fragment ions during multistage collisionally activated decomposition: An inducement to lose internal amino-acid residues. J. Am. Soc. Mass Spectrom. 18, 663-678 (2007)

56. Mouls, L., Aubagnac, J.L., Martinez, J., Enjalbal, C.: Low energy peptide fragmentations in an ESI-Q-TOF type mass spectrometer. $J$. Proteome Res. 6, 1378-1391 (2007)

57. Saminathan, I.S., Wang, X.S., Guo, Y., Krakovska, O., Voisin, S., Hopkinson, A.C.: Siu. K. W. M. The extent and effects of peptide sequence scrambling via formation of macrocyclic $b$ ions in model proteins. J. Am. Soc. Mass Spectrom. 21, 2085-2094 (2010)

58. Bythell, B.J., Maitre, P., Paizs, B.: Cyclization and rearrangement reactions of an fragment ions of protonated peptides. J. Am. Chem. Soc. 132, 14766-14779 (2010)

59. Yu, L., Tan, Y., Tsai, Y., Goodlett, D.R., Polfer, N.C.: On the relevance of peptide sequence permutations in shotgun proteomics studies. $J$. Proteome Res. 10, 2409-2416 (2011)

60. Goloborodko, A.A., Gorshkov, M.V., Good, D.M., Zubarev, R.A.: Sequence scrambling in shotgun proteomics is negligible. J. Am. Soc. Mass Spectrom. 22, 1121-1124 (2011) 